\title{
AURELIO ARTURO
}

\section{Juan Gustavo Cobo Borda}

En los cuadernos de Cántico, de veinticuatro páginas cada uno, dirigidos por Jaime Ibáñez en Bogotá, se hicieron presentes (1944-1948) la generación poética posterior a Piedra y Cielo y sugerentes propuestas extranjeras como las de Rilke y Paul Valery. En todo caso estos son los catorce cuadernos de Cántico, pues el número trece se repite:

1. Jaime Ibáñez

2. Francisco Luis Bernárdez

3. Andrés Holguín

4. Rainer María Rilke
5. Fernando Charry Lara

6. Paul Valery

7. Aurelio Arturo

8. Federico García Lorca

9. Jorge Rojas

10. Pablo Neruda

11. León de Greiff

12. Vicente Gerbasi

13. Julio Barrenechea

14. Porfirio Barba Jacob (reiterado en la numeración trece)

Se anunciaron, sin llegar a realizarse, entregas dedicadas a Eliot, Cocteau, Carrera

\section{RESUMEN:}

Juan Gustavo Cobo Borda, bogotano, además de poeta ha ejercido la crítica literaria. En el presente artículo presenta la obra del Aurelio Arturo que aparece a partir de la revista literaria Cántico, creada a mediados de los cuarenta por Jaime lbáñez y en la que participaron otros poetas colombianos como Fernando Charry Lara, Jorge Rojas y León de Greiff. Varios elementos se podrían señalar en la estética de Aurelio Arturo como es la poetización de elementos de la vida cotidiana, personajes sencillos del campo, el paisaje, la naturaleza, el ámbito de la infancia, entre otros, a los que "logra conferir un hálito legendario". De la obra de este gran poeta se destaca su Morada al Sur constituida por trece poemas que el autor pulió y corrigió a lo largo de su vida y dejó como muestra de perfección creativa.

\section{ABSTRACT:}

Juan Gustavo Cobo Borda, born in Bogota, in addition to being a poet, has been a literary critic. In this article he introduces the work of Aurelio Arturo, which appears simultaneously with the first issue of the literary magazine that was created by Jaime lbañez by the mid-1940s; and in which Colombian poets like Fernando Charry Lara, Jorge Rojas and León de Greiff, participated. Several elements could be identified in Aurelio Arturo's aesthetics, like the poeticizing of elements of everyday life, ordinary countryside characters, landscape, nature, the childhood ambiance, among others; to which he "succeeds in conveying a legendary aura". Of the work of this great poet, Morada al Sur is one of the most outstanding. It includes thirty poems which the author perfected and corrected throughout his life, and which he left as evidence of his creative perfection. 
Andrade y Jorge Gaitán Durán. Desde los poemas de su director Jaime Ibáñez, hasta los de algunos de sus colaboradores más próximos, como Andrés Holguín o Fernando Charry Lara, era evidente una inclinación al soneto, a elementos como la mariposa y la rosa, y a un tono añorante de esfumada sugerencia.

La vaga ciudad del recuerdo

surge en la memoria, perdida, como los restos de ciudades

en las arenas sumergidas,

Tal como canta Andrés Holguín en perceptible eco de "La ciudad sumergida", de Jorge Rojas: su homenaje a Tunja fechado en 1939.

Muchachas lejanas y ya fantasmales, bruma nostálgica; hay algo leve, de niebla y música, en esos correctos ejercicios de piano. Lo cual, por cierto, no sucede ni en García Lorca, Neruda o el propio León de Greiff. Al mismo tiempo la lectura de la "Leyenda del Amor y de la Muerte del Abanderado Cristóbal Rilke”, traducido por Alberto González Fernández, nos sorprende por encerrar en sus estrofas en prosa muchos de los temas de la poesía de Álvaro Mutis. Hidalgos de Francia y Borgoña, castillos de Bohemia, la chusma picaresca que

\section{RESEÑA AUTOR:}

Juan Gustavo Cobo Borda, poeta y ensayista bogotano. Su último libro Pintura simple sobre pintores colombianos, lo publicó Sic Editores de Bucaramanga en el 2005. Fue director durante una década (1973-1984) de la revista Eco, de Bogotá. Ha ocupado cargos diplomáticos en Buenos Aires, y Madrid y de embajador en Grecia. Miembro de número de la Academia Colombiana de la Lengua desde 1993, y correspondiente de la Lengua Española. Ha sido jurado del premio Juan Rulfo, de Guadalajara (México); del Rómulo Gallegos (Caracas), del Reina Sofía de Poesía Iberoamericana (Madrid) y del Neustad, Universidad de Oklahoma, (Estados Unidos). sigue al ejército y esos guerreros de hierro y muerte que cabalgan en pos de los perros turcos. También, en ese ambiente de cruzada, niños seducidos por una condesa y que mueren abrazados a su bandera. Mutis pedirá eternizar aquel instante en que unos muñones todavía sostienen otra bandera.

Charry Lara, por su parte, le pondrá de epígrafe a Noche del Alma estas líneas: "los días, que unos tras otros son la vida”, de Aurelio Arturo. Tenemos, entonces, frentes pensativas y almas taciturnas inclinadas sobre el misterio lunar de la poesía. Y en medio de este clima mental, en 1945, en el segundo año de Cántico, y en su entrega número siete, catorce poemas de Aurelio Arturo. Primer intento de ordenar su obra poética. "Una voz aislada, única en nuestra literatura".

También en estas palabras hay niebla, pero "la habla pulposa, casi palpable" de las mujeres disuelve una bruma que ya no es gris, sino sorpresivamente azul. Le confiere a "la feliz cantinela" una densidad corpórea, distante de la anterior evanescencia, pero no por ello carente de misterio. Por el contrario habla con una certeza visionaria:

“Este poema es un país que sueña”.

La mujer y la canción, la "verde algarabía de las hojas menudas”, y el recuerdo del viento, bajo un cielo de espadas, que hace vibrar y resonar al mundo, configuran el poema. Su núcleo será esa "célula viva, el instante imperecedero del paisaje".

Se trata de una naturaleza exultante y una geografía precisa: La ciudad de Almaguer. Un Sur que luego se volverá leyenda. "Una gran luz de sol y maravilla" 
que desciende y se transforma, en la noche balsámica, al ver crecer las mujeres, mientras caen de sus párpados "la sombra gota a gota”. Son los sentidos los que tejen el mundo, en hilos de luz, y son ellos quienes quedan impregnados por esa sensualidad absorbente.

Rumor hondo, huir sin fin, árbol suave: el país se convierte en mujer; "yo te besé, tierra del gozo", y unas aguas purificadoras y nutricias dan agilidad comunicativa a esos versos hondos que no solo reflejan las luces: las incorporan, las hacen suyas, en su devenir acompasado. La apropiación, que deviene una, naturaleza, mujer y poesía, proclama la conciencia de su logro:

"nadie ha de quitarme esta noche en que fuiste larga y desnuda carne vestida de mi aliento"

El poeta, con su voz, ha desceñido las raídas vestiduras. Pero la subjetividad pasional, el ahincar en el deseo, se abre y se expande en círculos cada más amplios: los hermanos, la madre, la gente que conoció en el sur. Nombres propios; Olinto Sierra, los Ulloas. La vieja casa, el rincón enigmático, los oscuros salones, y sus viajes inagotables que surgen de la música, la lectura o la ensoñación misma de la infancia. Incluso esa irradiación no se fija en un sueño, sino en un trabajo concreto. En la Rapsodia de Saulo, y refiriéndose al corte de los árboles, dirá Arturo: “Trabajar era bueno en el sur”. (A lo cual Arturo Camacho Ramírez replicó, con toda razón: "Trabajar no es bueno en ningún lado”).

En todo caso Arturo logra conferir a todo ello un hálito legendario, donde esos hombres rudos y broncos, de meneste- res cotidianos, quedan quinta esencia en un friso perdurable: Hombres "de ligeras canoas por los ríos salvajes", hombres quizás muertos que aún "viven en nuestras canciones". La faena y el alborozo, la lucha y el gemido amoroso, son apenas un pretexto para no perder esa comarca mágica, para no irse del río, para no cegar ni la fuente nutricia, ni las hablas primordiales. Termina el delgado cuadernillo de Cántico con la "Canción de hojas y lejanías" donde reitera "las lluvias de verdeante alborozo" y las "cocales de gozo". Un alfabeto, en definitiva, de celebración y consagración únicas.

Nueve de dichos poemas integrarían, en 1963, su libro canónico: Morada al Sur, compuesto de solo trece textos. Es decir que ya en 1945, estaba todo dicho. Como señala Hernando Cabarcas, Arturo, de 1945 a 1961, no publicará nuevos poemas. ¿Lo silenció el ejercicio del Derecho o ya no era necesario agregar algo nuevo? En todo caso, en 1973 cuando concluye la obra poética de Aurelio Arturo (1906-974) con poemas como Lluvias, Yerba o Tambores, vemos cómo, en tono y temática, no andaba muy lejos de estos orígenes. La misma sutil melodía que apenas sí se sostiene en esas palabras danzarinas y risueñas, que vencen la sequía. Ha suprimido, al final, la puntuación, y así el verso cae con ligereza, en una luminosa cascada de sonidos. La palabra fecunda la tierra, como una columna de luz. Una simiente que desciende del cielo, con la transparencia de un Tiziano, para ennoblecer a la vez el paisaje y la criatura humana.

Tres tradiciones pueden ofrecerse al poeta. El bardo, que simplemente canta. El profeta, que vislumbra y presagia. O el poeta como hacedor: para quien, el mundo 
es creación perpetua. Bien podemos adscribir a Aurelio Arturo a esta última y memorable estirpe. Y rastrear, en detalle, la doble vida que llevó y el logro integral y único que configura Morada al Sur.

\section{LA DOBLEVIDA}

En 1937 Aurelio Arturo obtiene su título de Doctor en Derecho en la universidad Externado de Colombia y su primer cargo público será como Juez Permanente de Policía. Profundizará en el Derecho Laboral y Penal y será nombrado, más tarde, Magistrado del Tribunal Administrativo de Nariño, a partir de 1953 y hasta 1956. En 1957 será nombrado Magistrado del Tribunal Superior de Popayán, donde permanecerá dos años. En 1959 es nombrado Magistrado del Tribunal Superior de Bogotá y Secretario General del Ministerio de Trabajo. En 1961, Magistrado del Tribunal Superior Militar en Bogotá. Nacido en 1906 en La Unión, Nariño, y muerto en Bogotá en 1974, celebramos ahora el primer centenario de uno de los más puros poetas colombianos. Esta fama perdurable se debe a un único libro, publicado por el Ministerio de Educación, en 1963: se titulaba Morada al Sur. Contiene sólo trece poemas, como ya dijimos, y su música se conserva intacta:

Una palabra vuelve, pero no es tu palabra, aunque fuera tu aliento que repite mi nombre, sino mi boca húmeda de tus besos perdidos, sino tus labios vivos en los míos, furtivos".

Para llegar a esta quintaesencia el camino había sido largo, lleno de desvíos. Se inició en 1927 con su Balada de Juan de la Cruz, y un año después ya vislumbra la ciudad futura, la ciudad colectiva de la hoz y el martillo, resumida en una sola palabra "para hablar a todas las razas de la tierra":

"Más fuerte que la luz es la palabra".

Lenin

Como Luis Tejada o Alberto Lleras Camargo, como el propio Borges, que en los años veinte compuso un libro titulado Los Salmos Rojos, que incluía poemas como el llamado Épica bolchevique, los jóvenes de todo el mundo estaban deslumbrados por el sol rojo que se levantaba en Moscú. Pero su fascinación por la revolución rusa no soslayaba, en el caso de Arturo, y ya en 1929, en las páginas de El Espectador su vocación americana: "concluyo, pues, creyendo en la posibilidad y florecimiento de un arte genuinamente americano sustentado en la tierra". "Somos tropicales y nuestra heredad es la faja donde la naturaleza se muestra más lujosa y espléndida, agobiada de savias y símbolos, calcinada por soles restallantes".

De ahí el poema Sol, aparecido por primera vez en el anuario Colombia en cifras (1945-1946), es incorporado luego a Morada al Sur:
Si yo cantara mi país un día, mi amigo el sol vendría a ayudarme con el viento dorado de los días inmensos y el antiguo rumor de los árboles.

Esta depuración en pos de lo esencial, este preferir los símbolos universales a las ideologías fechadas, contribuirán a perfilar mejor la figura que ya desde joven Arturo 
elegiría como la suya: la del cantor. La de la voz que señala y ennoblece toda cosa. La de quien busca un país en la entraña melódica de sus palabras. Al publicar el poema "Morada al Sur" en la revista de la Universidad Nacional en 1945 ya Aurelio Arturo lo había fundado para siempre. No es de extrañar, entonces, que de 1945 a 1961 como dijimos, no publicara ningún nuevo poema. Pero curiosamente su silencio solo contribuyó a volver más nítido y trascendental su canto.

La critica de la poesía es un absurdo. Ya es difícil decidir, y esta es sin embargo la única decisión posible,

si algo es poesía o no lo es.

Novalis

En el ya citado cuadernillo de Cántico no se incluye el poema titulado Morada al Sur pues éste aparecía en el mismo 1945 en la Revista de la Universidad Nacional, universidad a la cual se hallaba vinculado Jaime Ibáñez como Jefe de Extensión Cultural y quien en 1947 editara un libro muy afín al clima de Cántico. Cuatro conferencias sobre poetas dictadas por poetas: Fernando Charry Lara sobre Vicente Aleixandre; Jaime Ibáñez sobre Rilke; Andrés Holguín sobre Paul Valery y Daniel Arango sobre Antonio Machado. (Cuatro poetas del siglo XX, Bogotá: Universidad Nacional, 1947. 119 páginas)

La lectura del poema de Aurelio Arturo corrobora en su integridad el dictamen de Novalis, pero lo que quizás más sorprende en una relectura hoy del texto es el modo en que Arturo integró, en un poema a la vez ceñido, pero sugerente, todas sus anteriores intuiciones sobre la vida como algo bello en sí y sobre cómo ese trasfondo se trasluce en todos los signos cordiales con que la figura poética se expresa.

Hay una compenetración feliz y profunda entre la naturaleza y la palabra que la formula:

Oh voces manchadas de tenaz paisaje, llenas

del ruido de tan hermosos caballos que galopan bajo asombrosas ramas.

Y hay un reconocimiento constante de cómo la luz del sol vivifica e integra todos los momentos del canto, todos sus personajes: "y las mujeres enhebraron hilos de luz en sus dedos/ y los niños decían palabras doradas,..." dirá en el poema Sol.

Si la luz perfila con su fiel insistencia, es el viento, el que anima, impulsa y sostiene la materia misma del canto: su añoranza de un paraíso perdido, pero recobrado en esta elación simultánea de percepción de un ritmo musical y reconocimiento de un silencio pletórico de presencias grávidas. Cada una encierra un mundo.

El viento viene, viene vestido de follajes (...)

Y se duerme en el viejo portal donde el silencio

Es un maduro gajo de fragantes nostalgias.

Pero la casa, y la memoria de la misma, quedan trascendidas en una dimensión más amplia y abarcadora, resumida en versos ya célebres: "este poema es un país que sueña”. Allí donde bosques y lluvias, maderas y laúdes, hojas y vientos corren:

por los bellos países donde el verde es de todos los colores, 
los vientos que cantaron por los países de

Colombia.

Pero como sucede habitualmente. el fuego que anima al poema es el nocturno fuego de Eros, latente en la ensoñación, ávido de encarnar en un cuerpo que es a la vez tierra bendecida por el polen del deseo:

Qué noche de hojas suaves y de sombras de hojas y de sombras de tus párpados, la noche toda turba en ti, tendida, palpitante de aromas y astros,
La vista y el olfato dibujan ese continente inagotable, que se funde y confunde con el inicio de ese viaje bordeado de fábulas. La fascinación del narrar, del cuento inagotable, que brindara la nodriza con su "saliva melodiosa" y su par de lunas moradas, hace físico, corporal, todo el desarrollo del texto.

¿Por qué no me arrullas, oh noche mía amorosa,

en el valle de yerbas tibias de tu regazo?

Recobrar, para todos, esa noche y ese regazo primordial, es la razón última de este poema-y este libro-memorable. 